Polymer Journal, Vol. 38, No. 11, pp. 1114-1126 (2006)

(C) 2006 The Society of Polymer Science, Japan

\title{
Melt Miscibility and Mechanical Properties of Metallocene LLDPE blends with HDPE: Influence of $M_{\mathrm{w}}$ of LLDPE
}

\author{
Tayyab HAMEED ${ }^{1}$ and Ibnelwaleed A. HUSSEIN ${ }^{2, \dagger}$ \\ ${ }^{1}$ Center for Refining \& Petrochemicals, Research Institute \\ ${ }^{2}$ Department of Chemical Engineering, King Fahd University of Petroleum \& Minerals, \\ Dhahran 31261, Saudi Arabia
}

(Received March 22, 2006; Accepted August 8, 2006; Published September 21, 2006)

\begin{abstract}
The influence of $M_{\mathrm{w}}$ of LLDPE on the rheological, thermal and mechanical properties of m-LLDPE/ HDPE blends of low and high branch content (BC) was studied. Melt rheology of m-LLDPE blended with linear HDPE revealed strong influence of $M_{\mathrm{w}}$ on melt miscibility at both branching levels. Low $M_{\mathrm{w}} \mathrm{m}$-LLDPE/HDPE blends are suggested to be miscible at all compositions, while viscosity of high $M_{\mathrm{w}}$ m-LLDPE/HDPE blends showed negative deviation from log additivity suggesting layered morphology of these blends. The DSC results suggest that compatibility in the solid state is independent of $M_{\mathrm{w}}$ and $\mathrm{BC}$. For all blends studied, the HDPE-rich blends were found to contain single crystal populations suggesting high degree of cocrystallization, whereas, m-LLDPE rich phase showed separate crystallization. The melt miscibility and the crystallization of high BC m-LLDPE blends with HDPE are suggested to be controlled by different factors. Small strain mechanical properties of these blends were found to be a strong function of blend compatibility and the specific properties of the blend components.

[doi:10.1295/polymj.PJ2005254]

KEY WORDS LLDPE/HDPE Blends / Miscibility / Rheology / Mechanical Properties / DSC /

Molecular Weight /
\end{abstract}

Polyethylene blends are widely used to improve processing and tailor properties. ${ }^{1-7}$ However, this enhancement of processing and properties is dictated by phase homogeneity or heterogeneity of these blends in the melt and solid state. A large number of studies utilizing different techniques were devoted to investigate the phase morphology and characterization of polyolefin blends. These techniques include transmission electron spectroscopy,${ }^{8-11}$ small angle neutron scattering, ${ }^{11-13}$ differential scanning calorimetry, ${ }^{2,5,11,14-23}$ rheology, ${ }^{3,4,6,7,16-18,24-30}$ X-ray diffraction ${ }^{11,14,31}$ and more recently thermal fractionation techniques. ${ }^{33,34}$ Mechanical characterization of polyolefin blends has also been a subject of interest. ${ }^{2,5-7,20-23,30-32}$

Molecular parameters like branch content (BC), branch type, composition distribution, molecular weight $\left(M_{\mathrm{w}}\right)$ and molecular weight distribution (MWD) were found to be the key factors affecting the miscibility of polyolefin blends. Hill ${ }^{9}$ using transmission electron spectroscopy (TEM) found that $M_{\mathrm{w}}$ of linear HDPE had little influence on its miscibility with branched PEs. Alamo et al. ${ }^{12}$ observed that BC of the branched polyethylene (PE) is the most important parameter controlling the phase behavior of branched and linear PE blends. They reported no effect of $M_{\mathrm{w}}$ of branched PE on its miscibility with linear polyethylene for $M_{\mathrm{w}} \sim 100 \mathrm{~kg} / \mathrm{mol}$. On the other hand, Tanem and Stori ${ }^{10}$ reported strong influence of
$M_{\mathrm{w}}$ on miscibility of linear and branched PEs. They observed that low $M_{\mathrm{w}}$ of m-LLDPE enhanced its miscibility with linear HDPE. Recently, the authors have extensively studied the influence of molecular parameters on the miscibility of different polyethylenes ${ }^{21-27}$ using rheological techniques. $M_{\mathrm{w}}$ of m-LLDPE ${ }^{24}$ and $\mathrm{ZN}-\mathrm{LLDPE}^{28}$ was found to have a strong influence on its miscibility with LDPE. Low $M_{\mathrm{w}}$ m-LLDPE $(67 \mathrm{~kg} / \mathrm{mol})$ blends with LDPE were miscible at all compositions while the high $M_{\mathrm{w}}$ m-LLDPE $(108 \mathrm{~kg} /$ mol) blends showed partial miscibility at high LLDPE content and immiscibility at low LLDPE content with the same LDPE. ${ }^{25}$ Similar results were observed for low $-M_{\mathrm{w}}(50 \mathrm{~kg} / \mathrm{mol})$ and high $-M_{\mathrm{w}}(100 \mathrm{~kg} / \mathrm{mol}) \mathrm{ZN}-$ LLDPE blends with LDPE. ${ }^{28}$ Branch content of $\mathrm{m}$ LLDPE was also found to have a significant effect on its miscibility with LDPE. In two separate studies $^{26,29}$ it was shown that increased BC of m-LLDPE $\left(\sim 30 \mathrm{CH}_{3} / 1000 \mathrm{C}\right)$ enhanced its miscibility with LDPE compared to a low-BC m-LLDPE $\left(\sim 12 \mathrm{CH}_{3} /\right.$ $1000 \mathrm{C})$. However, influence of $\mathrm{BC}$ on miscibility of ZN-LLDPE/LDPE system was different when a LDPE of high-BC $\left(22 \mathrm{CH}_{3} / 1000 \mathrm{C}\right)$ was used. ${ }^{29}$

The effect of composition distribution (CD) of LLDPE on its miscibility with LDPE was also studied. ${ }^{26,29}$ Homogeneous ZN-LLDPE was found to be more miscible with LDPE (BC $\sim 9 \mathrm{CH}_{3} / 1000 \mathrm{C}$ ) compared to more homogeneous m-LLDPE of similar

${ }^{\dagger}$ To whom correspondence should be addressed (Tel: (966-3) 860-2235, Fax: (966-3) 860-4234, E-mail: ihussein@kfupm.edu.sa). 
BC $\left(13 \mathrm{CH}_{3} / 1000 \mathrm{C}\right) .{ }^{26}$ However, the results were opposite when a LDPE of high short chain branching $\left(\sim 22 \mathrm{CH}_{3} / 1000 \mathrm{C}\right)$ was used ${ }^{29}$ signifying the fact that the structure of LDPE also plays a role in the miscibility of these blends. Further, the effect of comonomer type of LLDPE on its miscibility with LDPE was also investigated. ${ }^{23,28}$ Whereas no influence of branch type (butene $v s$. hexene) was observed for single site m-LLDPE blends with LDPE, some improvement of miscibility was observed when the branch length was increased from two to four carbons (butene $v s$. octene) for ZN-LLDPE/LDPE systems. In all of the above blend systems, miscibility/immiscibility was composition dependent. We always observed miscibility or partial miscibility in the LLDPE rich phase whereas immiscibility usually appeared in the LDPE rich phase. It is also interesting to mention that rheology of immiscible LLDPE/LDPE systems always suggested emulsion rheology (positive deviation of viscosity and storage modulus from log-additivity or linear additivity) which is different from the phase behavior depicted by the LLDPE/HDPE systems as will be discussed later.

Studies on LLDPE/HDPE systems also revealed interesting results. The BC of LLDPE was found to have significant influence on miscibility of m-LLDPE/ HDPE blends while no effect of composition distribution (CD) of ZN-LLDPE vs. m-LLDPE was observed in low-BC $\left(\sim 13 \mathrm{CH}_{3} / 1000 \mathrm{C}\right)$ LLDPE/HDPE systems. ${ }^{24}$ Low BC m-LLDPE $\left(\sim 13 \mathrm{CH}_{3} / 1000 \mathrm{C}\right)$ was found to be miscible with HDPE, whereas, immiscibility increased in the high-BC $\left(32 \mathrm{CH}_{3} / 1000 \mathrm{C}\right)$ blends with HDPE. On the other hand, branch type (butene vs. hexene) did not influence the miscibility of m-LLDPE/HDPE systems. ${ }^{22}$ However, the immiscibility, whenever observed, was composition dependent and limited to LLDPE rich blends. Also, immiscible LLDPE/HDPE blends always revealed layered morphology as suggested by both rheological and molecular simulation studies in our group. ${ }^{24,35}$ On the other hand, emulsion rheology was observed in all LLDPE/LDPE blend systems investigated by different research groups.

Recently, Fang et al. $^{2}$ investigated melt miscibility of m-LLDPE/LDPE blends. Two sets of blends were prepared and compared to study the influence of short chain branching (SCB) and $M_{\mathrm{w}}$. A hexene based m-LLDPE $\left(\rho=0.918 \mathrm{~g} / \mathrm{cm}^{3}\right)$ and an octene based m-LLDPE $\left(\rho=0.902 \mathrm{~g} / \mathrm{cm}^{3}\right)$ with some long chain branching (LCB) were melt blended with two different LDPEs of varying melt indices. The hexene mLLDPE/LDPE blend was reported to be immiscible, whereas, octene m-LLDPE/LDPE blend was found to be miscible at all compositions. It was concluded that comparable $M_{\mathrm{w}}$, increased length of SCB (octene $v s$. hexene) and presence of LCB promotes miscibility of m-LLDPE/LDPE blends. An improved miscibility for octene m-LLDPE compared to hexene m-LLDPE with LDPE lead the authors to conclude that their results are in contradictions to those presented by Hameed and Hussein ${ }^{25}$ who found no influence of branch length (hexene $v s$. butene) on miscibility of m-LLPE/LDPE blends. The octene and hexene based m-LLDPEs used by Fang et al. differs not only in the type of SCB and presence of LCB but also in BC (LLDPEs used by Fang et al. had different densities). It is interesting that high BC octene m-LLDPE ( $\rho=$ $0.902 \mathrm{~g} / \mathrm{cm}^{3}$ ) was miscible with LDPE. This is in agreement with the findings of Hussein et al. ${ }^{26}$ who observed improved miscibility with increased $\mathrm{BC}$ of m-LLDPE. This comparison reveals that the different molecular parameters in LLDPE (such as BC and comonomer type) can interact to produce different results on LLDPE/LDPE miscibility. Hence, we assert that isolation of molecular interactions is very important in these studies. To reach decisive conclusions resin pairs need to be selected such that they do not differ in more than one molecular parameter.

Further, thermal and mechanical properties of polyethylene (PE) blends were also investigated. Zhao ${ }^{14}$ and Tanem and Stori ${ }^{15}$ observed that for the same BC ZN-LLDPE/HDPE blends are more compatible compared to m-LLDPE/HDPE blends. Tanem and Stori ${ }^{15}$ also reported an increase in solid state incompatibility/immiscibility with the increase in BC of m-LLDPE. The authors recently investigated the influence of branch content, composition distribution (CD) and comonomer type of LLDPE on thermal and mechanical behavior of its blends with HDPE and LDPE. ${ }^{21-23}$ Thermal and mechanical behavior of LLDPE/HDPE blends was influenced by $\mathrm{BC}$ and CD. ${ }^{21}$ To study the effect of $\mathrm{BC}$ and composition distribution the same resins were used as in ref 24. For m-LLDPE/HDPE blends, HDPE rich blends always showed single crystal population signifying strong compatibility, whereas, the m-LLDPE rich phase exhibited multiple peaks indicating separate crystallization of blend components irrespective of $\mathrm{BC}$ of $\mathrm{m}-$ LLDPE. However, BC did have a significant influence on the mechanical behavior of these blends. Further, ZN-LLDPE/HDPE blends showed single melting peaks and cocrystallization at all blend compositions, but they were not mechanically compatible. ${ }^{21}$ In another study, ${ }^{22}$ the comonomer type (butene $v s$. octene) in m-LLDPE was found to have little or no influence on the thermal and mechanical behavior of m-LLDPE/HDPE blends. Also, authors ${ }^{23}$ observed strong influence of $\mathrm{BC}$ and $\mathrm{CD}$ on thermal and mechanical behavior of LLDPE/LDPE blends. Highly branched m-LLDPE/LDPE blends showed more com- 
patible thermal and mechanical behavior compared to low BC m-LLDPE/HDPE blends. Similarly, the small strain mechanical properties of ZN-LLDPE/LDPE blends were superior to m-LLDPE/LDPE blends.

This work is presented to complement our previous work on the effect of different molecular parameters on melt miscibility and mechanical properties of PE blends. Here, we report our findings on the influence of $M_{\mathrm{w}}$ of m-LLDPE on rheological, thermal and mechanical properties of blends of m-LLDPE/HDPE systems. Two sets of metallocene resins were chosen such that $M_{\mathrm{w}}$ was the only primary molecular variable. One set represented low BC hexene m-LLDPEs and the other set, high BC butene m-LLDPEs. The two sets were blended with the same linear HDPE and results were compared to examine the influence of $M_{\mathrm{w}}$ of m-LLDPE on its miscibility with HDPE for the low and the high BC levels of m-LLDPEs.

\section{EXPERIMENTAL}

\section{Materials and Sample Preparation}

Four commercial samples of m-LLDPE, two hexene-copolymers named (m-EH1 and m-EH2) and two butene-copolymers (named m-EB1 and m-EB2) and a linear HDPE were supplied by ExxonMobil, Belgium. m-EH1 and m-EB1 denote the low $M_{\mathrm{w}}$ copolymers and m-EH2 and m-EB2 are the high $M_{\mathrm{w}}$ resins. The hexene-copolymers are used to study the effect of $M_{\mathrm{w}}$ at low BC level, whereas, the butenecopolymers were used to investigate the influence of $M_{\mathrm{w}}$ at high BC level. Studies ${ }^{22,25}$ by the authors showed that comonomer type of m-LLDPE has no influence on miscibility of its blends with HDPE. Hence, the results for hexene and butene m-LLDPE blends could be compared to study the effect of $M_{\mathrm{w}}$ at high and low BC level. The choice of resins was dictated by the availability of the proper type of resins. Table I provides characterization data such as density at room temperature, melt index (MI) at $190^{\circ} \mathrm{C}$ as provided by the manufacturer. The $\mathrm{BC}$ of copolymers was obtained from ${ }^{13} \mathrm{C}$ NMR as described in a previous publication. ${ }^{25}$ The $M_{\mathrm{n}}, M_{\mathrm{w}}$ and MWD were obtained by Waters 2000 GPC instrument. Tri-

Table I. Characterization of resins

\begin{tabular}{lccccc}
\hline Resin & $\begin{array}{c}\text { Density, } \\
\mathrm{g} / \mathrm{cm}^{3}\end{array}$ & $\begin{array}{c}\text { MI, } \\
\mathrm{g} / 10 \mathrm{~min}\end{array}$ & $\begin{array}{c}M_{\mathrm{w}}, \\
\mathrm{kg} / \mathrm{mol}\end{array}$ & $\mathrm{MWD}$ & $\mathrm{BC}^{*}$ \\
\hline $\mathrm{m}-\mathrm{EH} 1$ & 0.900 & 7.50 & 67 & 1.85 & 20.7 \\
$\mathrm{~m}-\mathrm{EH} 2$ & 0.900 & 1.20 & 107 & 1.83 & 18 \\
$\mathrm{~m}-\mathrm{EB} 1$ & 0.880 & 10.0 & 62 & 2.01 & 45 \\
$\mathrm{~m}-\mathrm{EB} 2$ & 0.880 & 0.8 & 125 & 1.81 & 42 \\
$\mathrm{HDPE}$ & 0.961 & 0.7 & 101 & 6.7 & 0 \\
\hline
\end{tabular}

${ }^{*} \mathrm{CH}_{3} / 1000 \mathrm{C}$. chlorobenzene was used as solvent at $135^{\circ} \mathrm{C}$ and standard polystyrene samples were utilized for calibration. The same linear HDPE was used in all of these blends.

At low-BC level, the effect of $M_{\mathrm{w}}$ of m-LLDPE, on the rheological, thermal and mechanical properties of its blends with HDPE was investigated by studying blends of m-EH1 and HDPE and results were compared to those obtained by blending $\mathrm{m}-\mathrm{EH} 2$ and HDPE. Similarly, results of $\mathrm{m}-\mathrm{EB} 1 / \mathrm{HDPE}$ and $\mathrm{m}-$ EB2/HDPE blends were compared to reveal the influence of $M_{\mathrm{w}}$ at high BC level. Sample pairs m-EH1 and $\mathrm{m}-\mathrm{EH} 2 ; \mathrm{m}-\mathrm{EB} 1$ and $\mathrm{m}-\mathrm{EB} 2$ were chosen in a way that $M_{\mathrm{w}}$ would be the only primary molecular parameter in this comparison. As shown in Table I, m-EH1 and $\mathrm{m}-\mathrm{EH} 2$ are of the same branch type (hexene), similar BC and MWD, and both LLDPEs are metallocene resins. Hence, comparison of $\mathrm{m}-\mathrm{EH} 1$ and $\mathrm{m}-\mathrm{EH} 2$ blends with HDPE is expected to reveal the effect of $M_{\mathrm{w}}$ on rheological, thermal and mechanical characteristics of m-LLDPE/HDPE systems at low-BC level. On the other hand, the comparison of m-EB1 and m-EB2 blends with HDPE is likely to show the influence of $M_{\mathrm{w}}$, at high BC levels. The HDPE and LLDPE resins used in this study were conditioned (or blended) in a Haake PolyDrive melt blender in the presence of extra $1000 \mathrm{ppm}$ of antioxidant to avoid degradation. Conditions and details of melt blending and sample preparation are given elsewhere. ${ }^{25}$

\section{Rheological Measurements}

Dynamic measurements were carried out in an ARES constant strain rheometer. Discs of polymer samples of $2 \mathrm{~mm}$ thickness were used. In all tests, cone-and-plate geometry with cone-angle $0.1 \mathrm{rad}$ and platen diameter $25 \mathrm{~mm}$ was used. Dynamic viscoelastic properties were measured in the range of 100 to $0.01 \mathrm{rad} / \mathrm{s}$ at $15 \%$ strain following a strain sweep to determine the linear viscoelastic range. All tests were performed at $190^{\circ} \mathrm{C}$ in a nitrogen environment to protect the samples from degradation during testing.

\section{Differential Scanning Calorimetry (DSC)}

Thermal analysis was performed with a TA Instruments Q1000 DSC equipped with TA Universal analyzer software, and nitrogen gas flow was used as a blanket. The samples were heated from $25^{\circ} \mathrm{C}$ to $160^{\circ} \mathrm{C}$ at $10^{\circ} \mathrm{C} / \mathrm{min}$, held at $160^{\circ} \mathrm{C}$. Details of the testing procedure and calculation of crystallinity are given elsewhere. ${ }^{36}$

\section{Mechanical Testing}

Dog-bone samples were prepared according to ASTM D638 (type V). The tensile tests were performed on Instron 5567 tensile testing machine at 


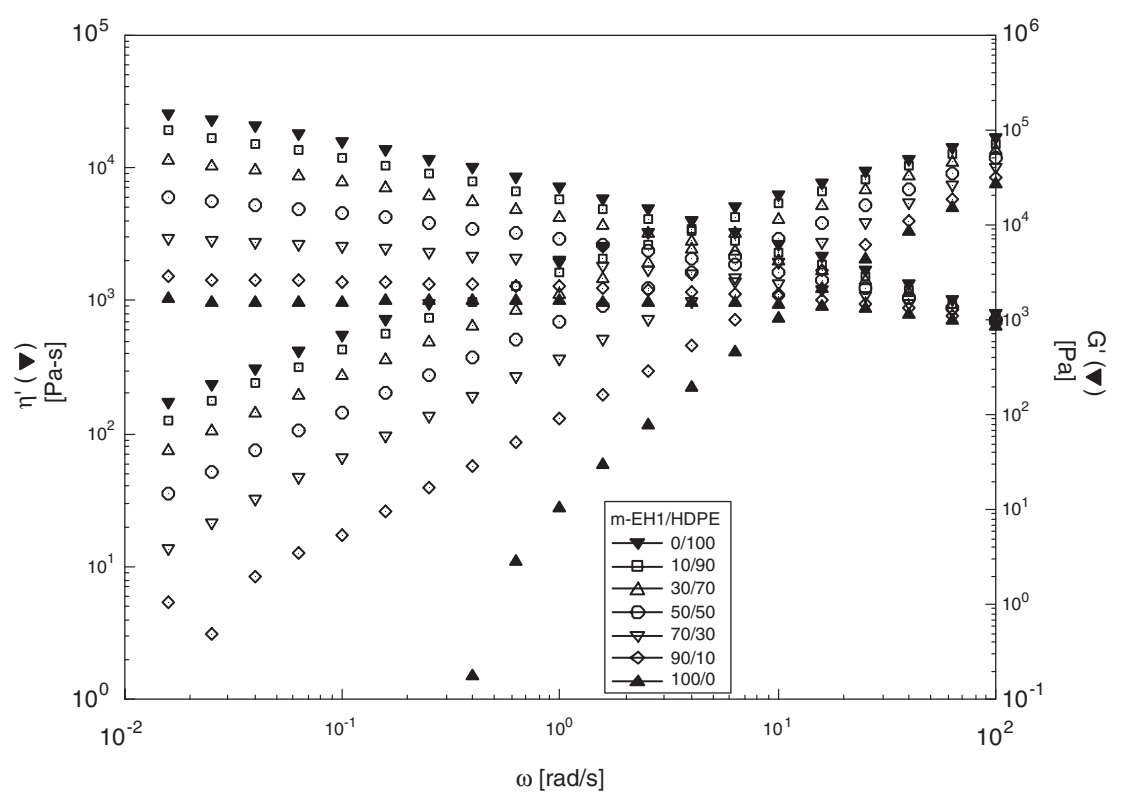

(a)

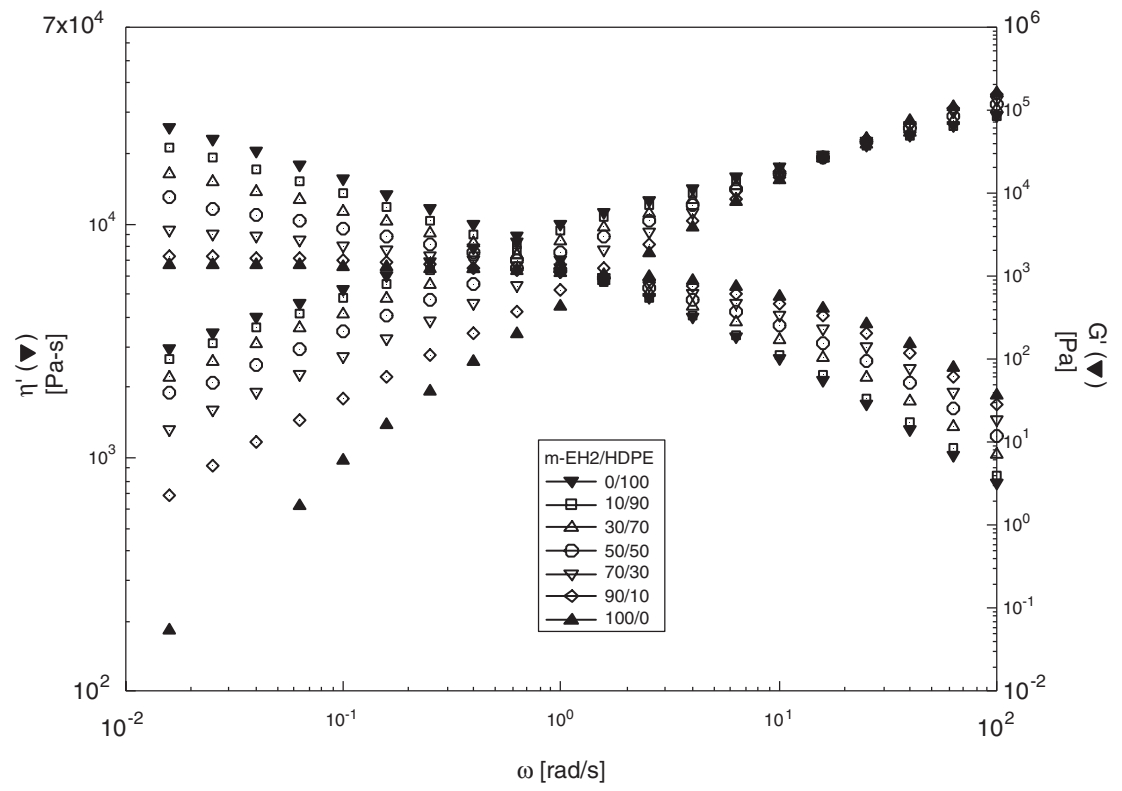

(b)

Figure 1. (a) $\eta^{\prime}(\omega)$ and $\mathrm{G}^{\prime}(\omega)$ for blends of low $M_{\mathrm{w}} \mathrm{m}-\mathrm{EH} 1$ and $\operatorname{HDPE}\left(T_{\operatorname{mix}}=190^{\circ} \mathrm{C}, T_{\text {test }}=190^{\circ} \mathrm{C}, \gamma^{\circ}=15 \%\right)$. (b) $\eta^{\prime}(\omega)$ and $\mathrm{G}^{\prime}(\omega)$ for blends of high $M_{\mathrm{w}} \mathrm{m}-\mathrm{EH} 2$ and $\operatorname{HDPE}\left(T_{\text {mix }}=190^{\circ} \mathrm{C}, T_{\text {test }}=190^{\circ} \mathrm{C}, \gamma^{\circ}=15 \%\right)$.

room temperature $\left(25^{\circ} \mathrm{C}\right)$. The gauge length was kept at $25 \mathrm{~mm}$ with a crosshead speed of $125 \mathrm{~mm} / \mathrm{min}$. All samples ruptured within 0.5 to $5 \mathrm{~min}$ of testing time. All the reported mechanical properties are based on an average of a minimum of five specimens.

\section{RESULTS AND DISCUSSION}

\section{Rheology of Melt Blends}

Figures $1 \mathrm{a}$ and $1 \mathrm{~b}$ show dynamic viscoelastic data for the low BC m-EH1 (low $M_{\mathrm{w}}$ ) and m-EH2 (high $M_{\mathrm{w}}$ ) blends with HDPE. Low frequency $(\omega)$ data is very sensitive to molecular structure and is particular- ly useful in interpreting morphology and high shear rates could induce miscibility [ref 25 and references therein]. $\mathrm{m}-\mathrm{EH} 1$ shows a zero shear viscosity $\left(\eta_{\mathrm{o}}\right)$ plateau which expands over almost three decades and shows little shear thinning over the range of $\omega$ studied. m-EH1 exhibits the lowest $\eta^{\prime}$ and $\mathrm{G}^{\prime}$ values over the whole $\omega$ range mainly due to its low $M_{\mathrm{w}} \cdot \eta^{\prime}$ and $\mathrm{G}^{\prime}$ of $\mathrm{m}-\mathrm{EH} 1 / \mathrm{HDPE}$ blends are found to lie in between the pure components at all $\omega$. A gradual increase in $\eta^{\prime}$ and $\mathrm{G}^{\prime}$ is observed with an increase in the HDPE content. This behavior suggests miscibility of the low $M_{\mathrm{w}}$ pair. On the other hand, high $M_{\mathrm{w}} \mathrm{m}-\mathrm{EH} 2 /$ HDPE blends (Figure 1b) follow a somewhat different 


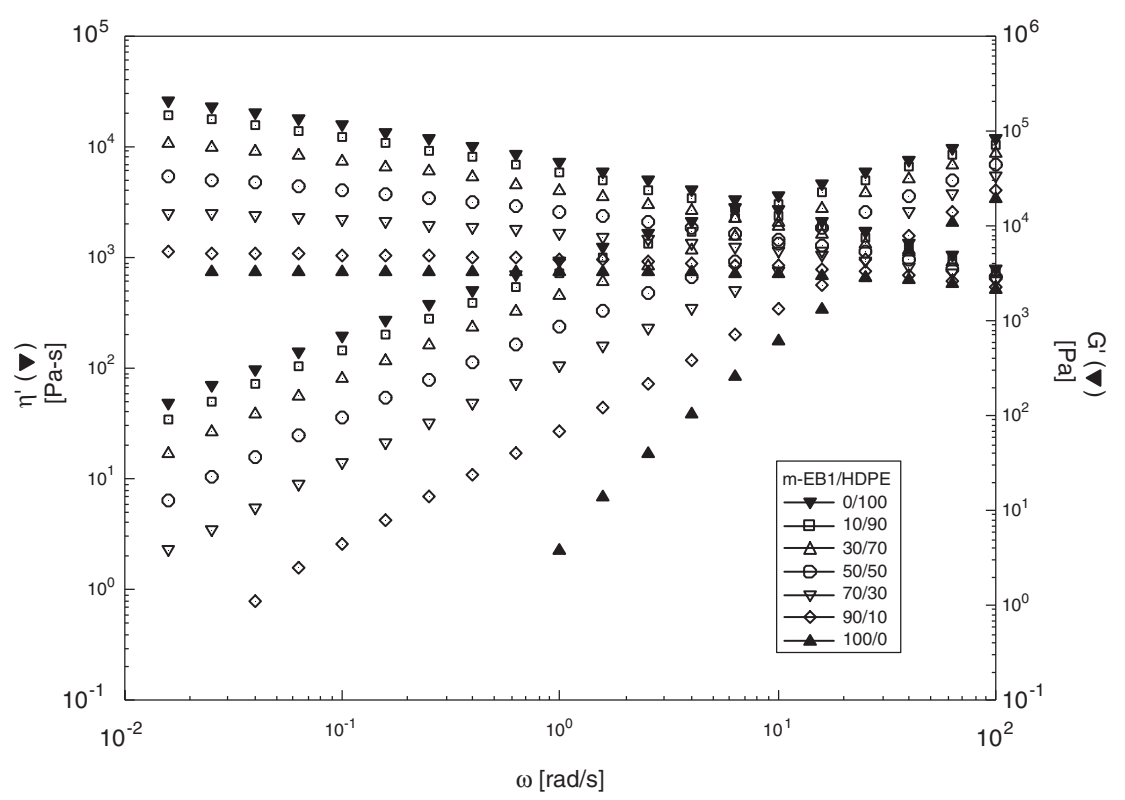

(a)

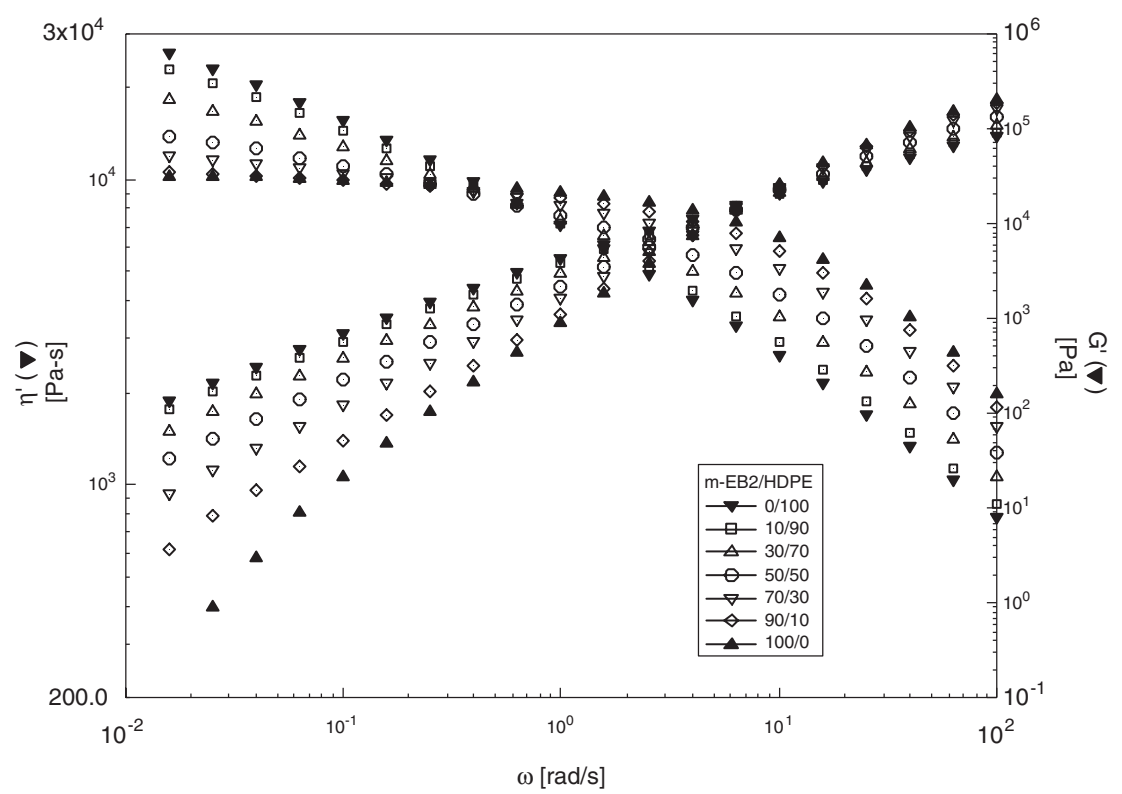

(b)

Figure 2. (a) $\eta^{\prime}(\omega)$ and $\mathrm{G}^{\prime}(\omega)$ for blends of low $M_{\mathrm{w}} \mathrm{m}$-EB 1 and $\operatorname{HDPE}\left(T_{\operatorname{mix}}=190{ }^{\circ} \mathrm{C}, T_{\text {test }}=190{ }^{\circ} \mathrm{C}, \gamma^{\circ}=15 \%\right)$. (b) $\eta^{\prime}(\omega)$ and $\mathrm{G}^{\prime}(\omega)$ for blends of high $M_{\mathrm{w}} \mathrm{m}$-EB2 and $\operatorname{HDPE}\left(T_{\text {mix }}=190^{\circ} \mathrm{C}, T_{\text {test }}=190^{\circ} \mathrm{C}, \gamma^{\circ}=15 \%\right)$.

behavior. Once again, HDPE is the component of the highest viscosity and elasticity, however, the viscosity and elasticity of $\mathrm{m}-\mathrm{EH} 2$ is comparatively higher than that observed for m-EH1 because of its high $M_{\mathrm{w}}$. The Newtonian viscosity plateau has reduced to two decades and a shear thinning behavior is quite visible. For all blends $\eta^{\prime}$ and $\mathrm{G}^{\prime}$ are found to lie between the pure components and the behavior of the high and low $M_{\mathrm{w}}$ pairs was similar.

To fully understand the influence of $M_{\mathrm{w}}$ on miscibility of LLDPE/HDPE blends another set of resins with differing $M_{\mathrm{w}}$ at higher $\mathrm{BC}$ level $\left(\sim 40 \mathrm{CH}_{3} /\right.$ $1000 \mathrm{C}$ ) were blended with HDPE. m-EB1 is a low
$M_{\mathrm{w}}$ butene-ethylene copolymer, while m-EB2 is a high $M_{\mathrm{w}}$ butene-ethylene copolymer. Figures $2 \mathrm{a}$ and $2 \mathrm{~b}$ show the viscoelastic properties $\eta^{\prime}(\omega)$ and $\mathrm{G}^{\prime}(\omega)$ for $\mathrm{m}$-EB1 and m-EB2 blends with HDPE. m-EB1 shows an extended zero shear viscosity, $\eta_{\mathrm{o}}$, plateau and negligible shear thinning behavior. The viscoelastic properties for blends change gradually with the addition of m-EB1. However, the high $M_{\mathrm{w}} \mathrm{m}-\mathrm{EB} 2$ shows a Newtonian plateau extended over almost a decade. It is interesting to note that the comparison of the high $\mathrm{BC}$ and the low $\mathrm{BC} \mathrm{m}-\mathrm{EH}$ resins of similar $M_{\mathrm{w}}$ reveals more pronounced shear thinning in high BC m-LLDPE. This is a direct consequence of high 

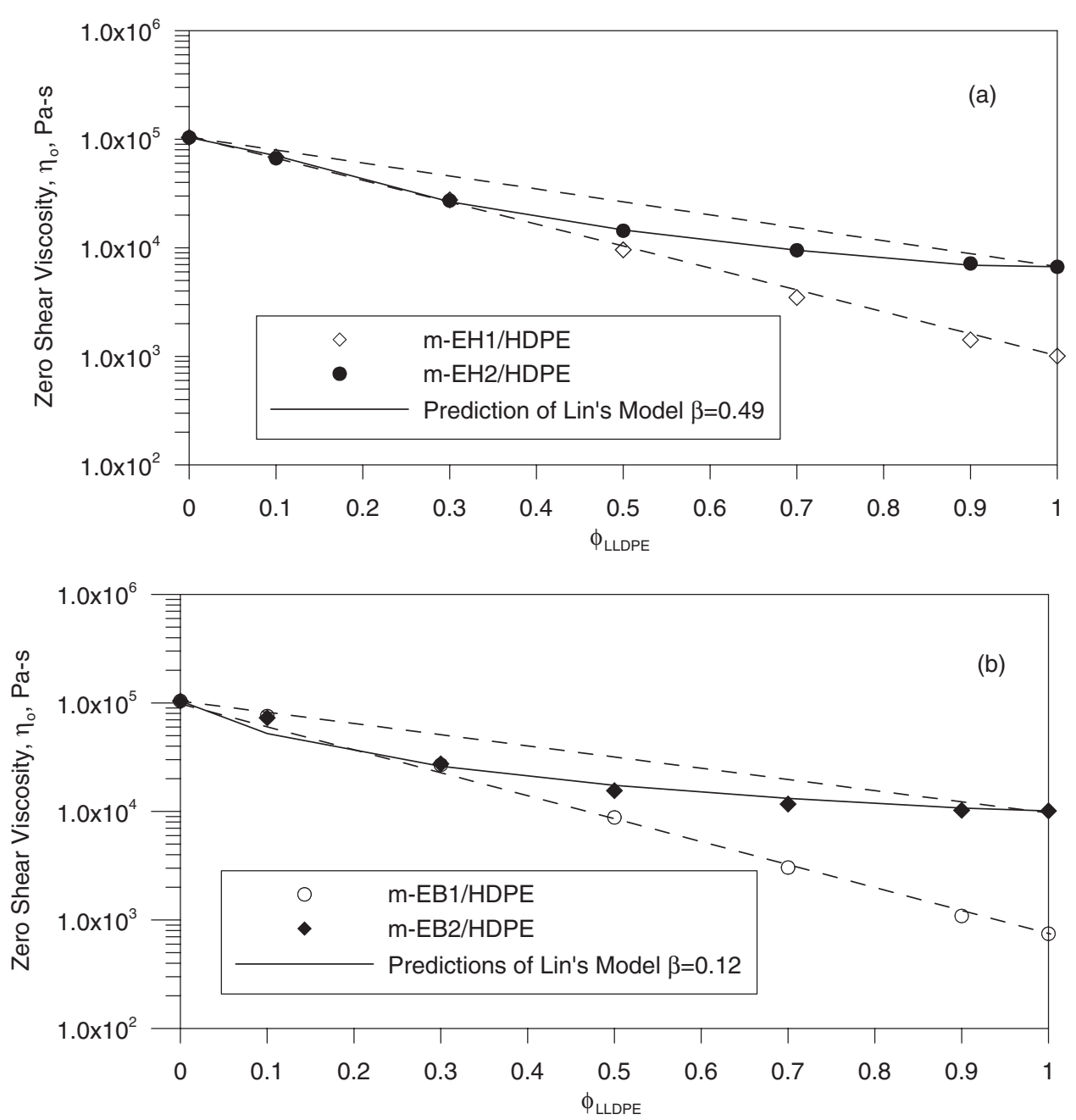

Figure 3. $\eta_{\mathrm{o}}(\phi)$ as computed from Carreau model; (a) m-EH1/HDPE; m-EH2/HDPE blends. (b) m-EB1/HDPE; m-EB2/HDPE blends $\left(T_{\text {mix }}=190^{\circ} \mathrm{C}, T_{\text {test }}=190^{\circ} \mathrm{C}, \gamma^{\circ}=15 \%\right)$.

$\mathrm{BC}$ and poor branch distribution in highly branched m-LLDPE. ${ }^{15,37}$ The viscosity and elasticity of $\mathrm{m}$ EB2/HDPE blends are found to lie between those of pure resins.

Figures $3 \mathrm{a}$ and $3 \mathrm{~b}$ show $\eta_{\mathrm{o}}$ plotted against blend composition for low $\mathrm{BC}$ and high $\mathrm{BC}$ blends respectively. $\eta_{\mathrm{o}}$ for low $M_{\mathrm{w}} \mathrm{m}-\mathrm{EH} 1$ and m-EB1 blends with HDPE are found to follow log additivity over the whole composition range suggesting miscibility of these blends. However, blends containing high $M_{\mathrm{w}}$ $\mathrm{m}-\mathrm{EH} 2$ and $\mathrm{m}-\mathrm{EB} 2$ show negative deviation from $\log$ additivity.

Utracki ${ }^{38}$ has suggested an equation to predict the negative and positive deviation behavior in polymer blends.

$$
\log \eta=\log \eta_{\mathrm{L}}+\Delta \log \eta^{\mathrm{E}}
$$

in which the first term describes the negative deviation behavior with interlayer slip first presented by $\operatorname{Lin}^{39}$

$\log \eta_{\mathrm{L}}=-\log \left[1+\beta\left(\phi_{1} \phi_{2}\right)^{0.5}\right]-\log \left(\phi_{1} / \eta_{1}+\phi_{2} / \eta_{2}\right)$ where $\beta$ in the interlayer slip factor. For $\beta \rightarrow 0$ fluidity-additivity equation is recovered. ${ }^{40}$ The second term $\left(\Delta \log \eta^{\mathrm{E}}\right)$ was introduced to predict the positive deviation behavior resulting from emulsion morphology of immiscible blends. This term must be zero at $\phi_{\mathrm{i}}=0$ and reach maximum at the phase inversion concentration $\phi_{\mathrm{i}}=\phi_{\mathrm{i} I}$

$$
\Delta \log \eta^{\mathrm{E}}=\eta_{\max }\left\{1-\left[\left(\phi_{1}-\phi_{1 I}\right)^{2} /\left(\phi_{1} \phi_{2 I}^{2}+\phi_{2} \phi_{1 I}^{2}\right)\right]\right\}
$$

where $\eta_{\max }$ is a parameter to quantify the positive deviation behavior.

Since no positive deviation behavior was observed for the blends investigated in this study, we used eq 2 to predict the negative deviation behavior. The model predictions are shown in Figures $3 a$ and $3 b$ as bold line. The agreement between experimental and predicted values is very good. The only disagreement observed is for $10 \% \mathrm{~m}-\mathrm{EB} 2 / \mathrm{HDPE}$ blend where the viscosity of the blend falls on log additivity and hence is a miscible blend. So, the high $M_{\mathrm{w}}$ LLDPE/HDPE blends are suggested to have layered morphology irre- 


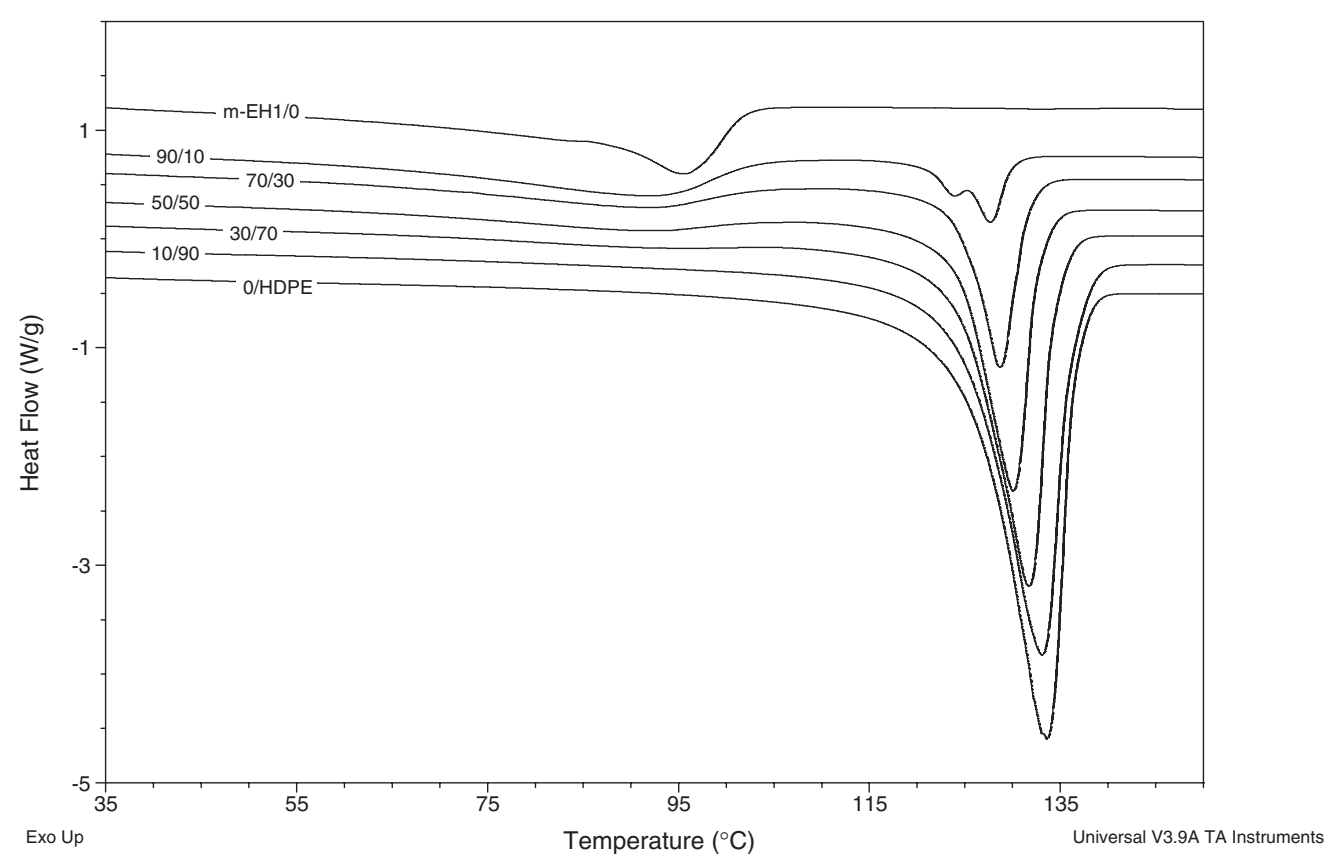

(a)

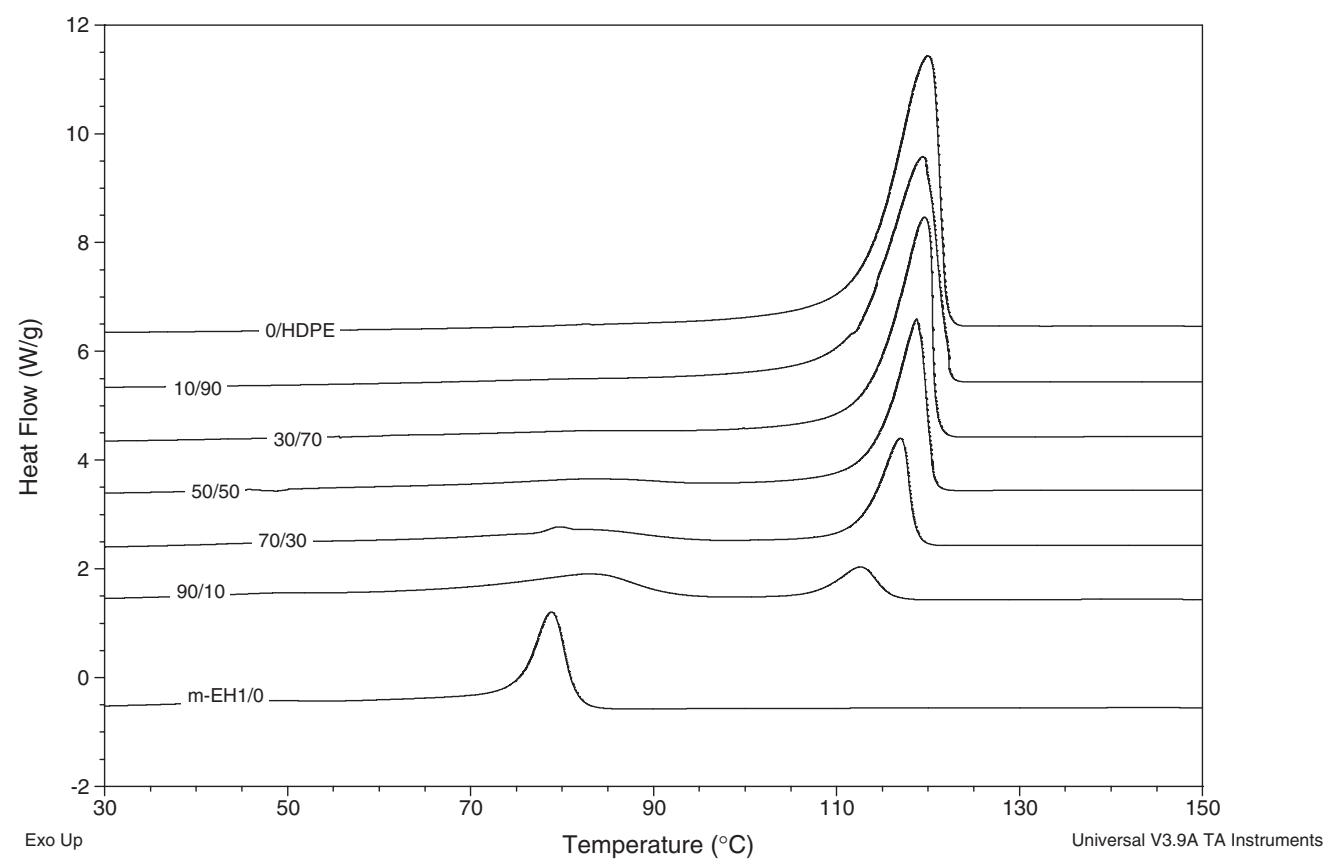

(b)

Figure 4. (a) DSC heating scans for m-EH1/HDPE blends. (b) DSC cooling scans for m-EH1/HDPE blends.

spective of their branch content. These results are in agreement with the previously reported results in literature. Tanem and Stori ${ }^{10}$ reported strong influence of $M_{\mathrm{w}}$ on miscibility of linear and branched PEs, whereas, authors have shown a similar effect for m-LLDPE/ LDPE system. ${ }^{25}$ On the other hand, influence of BC on miscibility of linear and branched PEs is well established through various techniques. Alamo et al. ${ }^{12}$ and $\mathrm{Choi}^{41}$ have reported a critical branch content of $40 \mathrm{CH}_{3} / 1000 \mathrm{C}$ for phase separation. In a previous study, our group confirmed by molecular dynamics simulations that negative deviation behavior in the melt rheology results in a layered morphology for HDPE/LLDPE blends. ${ }^{35}$

To conclude, the melt rheology of m-LLDPE/ HDPE blends suggests strong influence of $M_{\mathrm{w}}$ of mLLDPE on its miscibility with HDPE at low BC $\left(\sim 20 \mathrm{CH}_{3} / 1000 \mathrm{C}\right)$ and high $\mathrm{BC}\left(\sim 40 \mathrm{CH}_{3} / 1000 \mathrm{C}\right)$ levels. The low $M_{\mathrm{w}}$ m-LLDPE are suggested to be miscible with HDPE at all compositions. However, the high $M_{\mathrm{w}}$ m-LLDPE/HDPE blends exhibited negative deviation behavior and the experimental data 


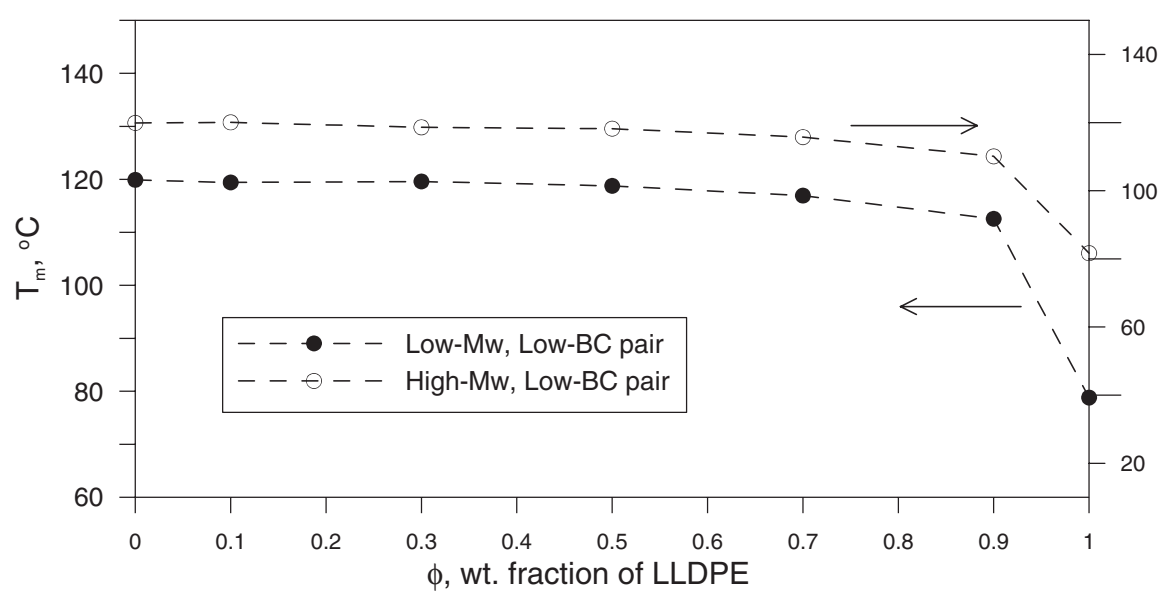

Figure 5. Peak melting temperature as a function of composition; (a) m-EH1/HDPE (low- $M_{\mathrm{w}}$ ); (b) m-EH2/HDPE blends (high- $M_{\mathrm{w}}$ ).

were well predicted by theoretical models suggesting layered morphology in these blends. These results reveal the fact that at high $\mathrm{BC}$ the $M_{\mathrm{w}}$ of m-LLDPE has a strong influence on its miscibility with HDPE.

\section{Differential Scanning Calorimetry}

Figure $4 \mathrm{a}$ shows the second heating curves for $\mathrm{m}$-EH1/HDPE blends and pure resins. HDPE shows a very sharp single peak. It is also the component displaying the highest peak melting temperature, $T_{\mathrm{m}}$, $\left(133.6^{\circ} \mathrm{C}\right)$, and crystallinity $(84.32 \%)$. This is due to the linear structure of the HDPE, although the sample has a high MWD (PDI $=6.0)$. The low $M_{\mathrm{w}} \mathrm{m}-\mathrm{EH} 1$, on the other hand, shows a bimodal and relatively broad peak due to its branching. The bimodal response is composed of a low temperature shoulder and a high temperature peak at $95.56^{\circ} \mathrm{C}$. This phenomenon is actually the result of an overlap of two peaks resulting from reorganization during scanning. ${ }^{34}$ The difference in the behavior of HDPE and m-EH1 is a result of the branching, since $\mathrm{m}-\mathrm{EH} 1$ has short chain branching while HDPE has a linear structure. All HDPE-rich blends $(\phi=0.0-0.3)$ show a single melting peak suggesting a single crystal population and cocrystallization in these blends. However, m-EH1 rich blends $(\phi=0.5-0.9)$ show multiple peaks. The high temperature peak is attributed to the cocrystallization of linear fractions of m-EH1 and HDPE, whereas, the broad shoulder at lower temperature represents melting of lamellae formed by branched m-EH1 chains. ${ }^{21-23}$

Figure $4 \mathrm{~b}$ displays the cooling curves for m-EH1/ HDPE blends. A single sharp crystallization peak with $T_{\mathrm{c}}=119.9^{\circ} \mathrm{C}$ is observed for HDPE, whereas, mEH1 shows a lower peak at $T_{\mathrm{c}}=78.82^{\circ} \mathrm{C}$ and a very broad shoulder at a lower temperature. On the addition of just $10 \%$ HDPE to m-EH1, two new peaks have appeared at $85^{\circ} \mathrm{C}$ and $112.5^{\circ} \mathrm{C}$. These melting temperatures represent two types of crystal population. The relatively linear chains in m-EH1 cocrystal- lize with HDPE and melt at $\sim 112.5^{\circ} \mathrm{C}$, while the branched segments form a separate crystal population observed as a broad peak at $85^{\circ} \mathrm{C}$. On the other hand, the HDPE rich blends form a single crystal population represented by a unique peak. The heating and cooling curves suggest high degree of solid state compatibility (single $T_{\mathrm{m}}$ ) in HDPE rich blends. However, multiple peaks suggest the presence of multiple crystal types. Whether this will lead to solid-state compatibility or incompatibility depends on the mechanical properties that will be discussed later.

To further elaborate the results $T_{\mathrm{m}}$ and percentage crystallinities of pure polymers and their blends are plotted against blend composition in Figures 5 and 6 , respectively. HDPE rich blends show a single melting peak with $T_{\mathrm{m}}$ decreases almost linearly with addition of $\mathrm{m}-\mathrm{EH} 1$. This trend is an evidence of some cocrystallization in all blends. HDPE melts in the presence of molten LLDPE (which melts at a lower temperature) which depresses the $T_{\mathrm{m}}$ of HDPE. ${ }^{34}$ The measured crystallinity of the neat polymers and their blends are plotted against blend composition in Figure 6 . The solid line shows the calculated crystallinity based on the assumption that the blend components form separate crystals. In all blends, measured crystallinity is less than the crystallinity based on separate crystallization. A low crystallinity of blend compared to the pure blend components has been taken as an argument in favor of cocrystallization. ${ }^{15,16,20}$ Hence, in all m-EH1/HDPE some cocrystallization has taken place. However, a unique peak in HDPErich blends suggests the presence of only a single population of cocrystals; whereas, multiple peaks in $\mathrm{m}$-EH1-rich blends suggest the presence of cocrystal and separate crystal populations.

Heating and cooling thermograms for high $M_{\mathrm{w}}$ m-EH2/HDPE were very similar to those of m-EH1/ HDPE blends. Hence the thermograms are not shown. The melting, crystallization temperatures and crystal- 

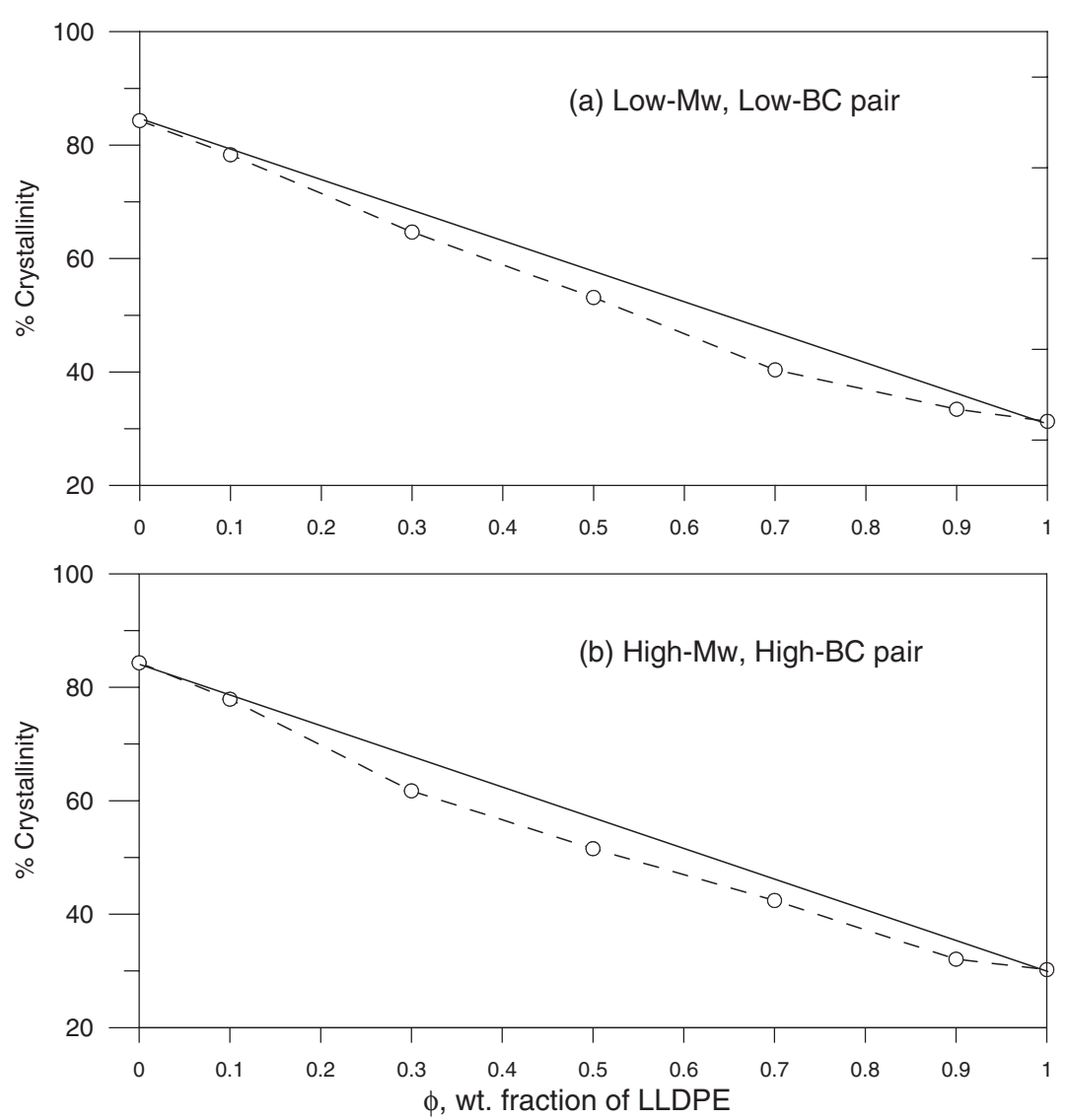

Figure 6. Percentage crystallinity as a function of composition; (a) m-EH1/HDPE; (b) m-EH2/HDPE blends.

Table II. $T_{\mathrm{m} 1}$ and $T_{\mathrm{c} 1}$ denote the peak meting temperature and crystallization temperatures of the high temperature peak in the blend. $T_{\mathrm{m} 2}$ and $T_{\mathrm{c} 2}$ denote the melting and crystallization temperature of the low melting peak in the blend. $\omega_{\mathrm{o}}$ is the observed crystallinity, whereas, $\omega_{\mathrm{c}}$

is the calculated crystallinity assuming completely separate crystallization of blend components

\begin{tabular}{|c|c|c|c|c|c|c|}
\hline \multirow{2}{*}{ Blend } & \multicolumn{2}{|c|}{$T_{\mathrm{m}}$} & \multicolumn{2}{|c|}{$T_{\mathrm{c}}$} & \multicolumn{2}{|c|}{$\omega$} \\
\hline & $T_{\mathrm{m} 1}$ & $T_{\mathrm{m} 2}$ & $T_{\mathrm{c} 1}$ & $T_{\mathrm{c} 2}$ & $\omega_{\mathrm{o}}$ & $\omega_{\mathrm{c}}$ \\
\hline $\mathrm{HDPE} / 0(\mathrm{~m}-\mathrm{EH} 2)$ & 133.6 & & 120.0 & & 84.3 & 84.3 \\
\hline $10 / 90$ & 132.3 & & 120.2 & & 77.9 & 78.9 \\
\hline $30 / 70$ & 130.9 & & 119.2 & & 61.7 & 68.1 \\
\hline $50 / 50$ & 129.9 & 91.34 & 118.1 & 85.0 & 51.6 & 57.3 \\
\hline $70 / 30$ & 127.1 & 91.32 & 115.6 & 83.7 & 42.4 & 46.5 \\
\hline $90 / 10$ & 126.14 & 93.3 & 110.0 & 84.4 & 32.1 & 35.6 \\
\hline $0(\mathrm{HDPE}) / \mathrm{m}-\mathrm{EH} 2$ & & 96.5 & & 81.6 & 30.2 & 30.2 \\
\hline HDPE/0(m-EB2) & 133.6 & & 120.0 & & 84.3 & 84.3 \\
\hline $10 / 90$ & 132.9 & & 119.8 & & 71.9 & 65.9 \\
\hline $30 / 70$ & 132.2 & & 119.8 & & 54.6 & 41.7 \\
\hline $50 / 50$ & 130.1 & 59.5 & 118.8 & 48.8 & 41.6 & 26.6 \\
\hline $70 / 30$ & 128.36 & 58.8 & 116.7 & 51.2 & 29.1 & 16.9 \\
\hline $90 / 10$ & 127.74 & 58.8 & 111.8 & 51.7 & 18.9 & 12.4 \\
\hline 0(HDPE)/m-EB2 & & 62.75 & & 48.8 & 11.7 & 11.7 \\
\hline
\end{tabular}

linity data is presented in Table II. HDPE and HDPErich blends are found to show one $T_{\mathrm{m}}$ suggesting a single cocrystal population, whereas, $\mathrm{m}-\mathrm{EH} 2$ and $\mathrm{m}-$
EH2-rich blends show multiple peaks (peak melting temperatures) suggesting cocrystal and separate crystal populations. However, in all blends the observed crystallinity is less than the crystallinity calculated based on separate crystallization. This suggests that some degree of cocrystallization is always there. These results are very similar to those of low $M_{\mathrm{w}}$ m-EH1/HDPE blends. The major difference between $\mathrm{m}-\mathrm{EH} 1$ and $\mathrm{m}-\mathrm{EH} 2$ resins is $M_{\mathrm{w}}$. Earlier, BC and composition distribution were reported to influence solid state compatibility of PE blends. ${ }^{10-12,14-19,21-23}$ Since the BC for $\mathrm{m}-\mathrm{EH} 1$ and $\mathrm{m}-\mathrm{EH} 2$ are similar $(\mathrm{BC}=18,20.7$ branches $/ 1000 \mathrm{C})$ and are both produced by metallocene catalyst, similarity in solid state morphology suggest no influence of $M_{\mathrm{w}}$ on the compatibility of $\mathrm{m}-\mathrm{EH} / \mathrm{HDPE}$ blends.

Figure 7a shows the second heating scans for high BC low $M_{\mathrm{w}} \mathrm{m}-\mathrm{EB} 1 / \mathrm{HDPE}$ blends and the pure resins. HDPE and HDPE-rich blends show a single melting peak. m-EB1 shows a very broad melting peak $\left(\sim 62.34^{\circ} \mathrm{C}\right)$ resulting from the high branch content of this resin. High degree of branching hinders chain folding and does not allow the formation of thicker lamellas. m-EB1 rich blends show multiple peaks suggesting cocrystallization as well as separate crystallization as discussed earlier. Similar conclusions could be drawn from cooling curves (Figure $7 \mathrm{~b}$ ), $T_{\mathrm{m}}$ 


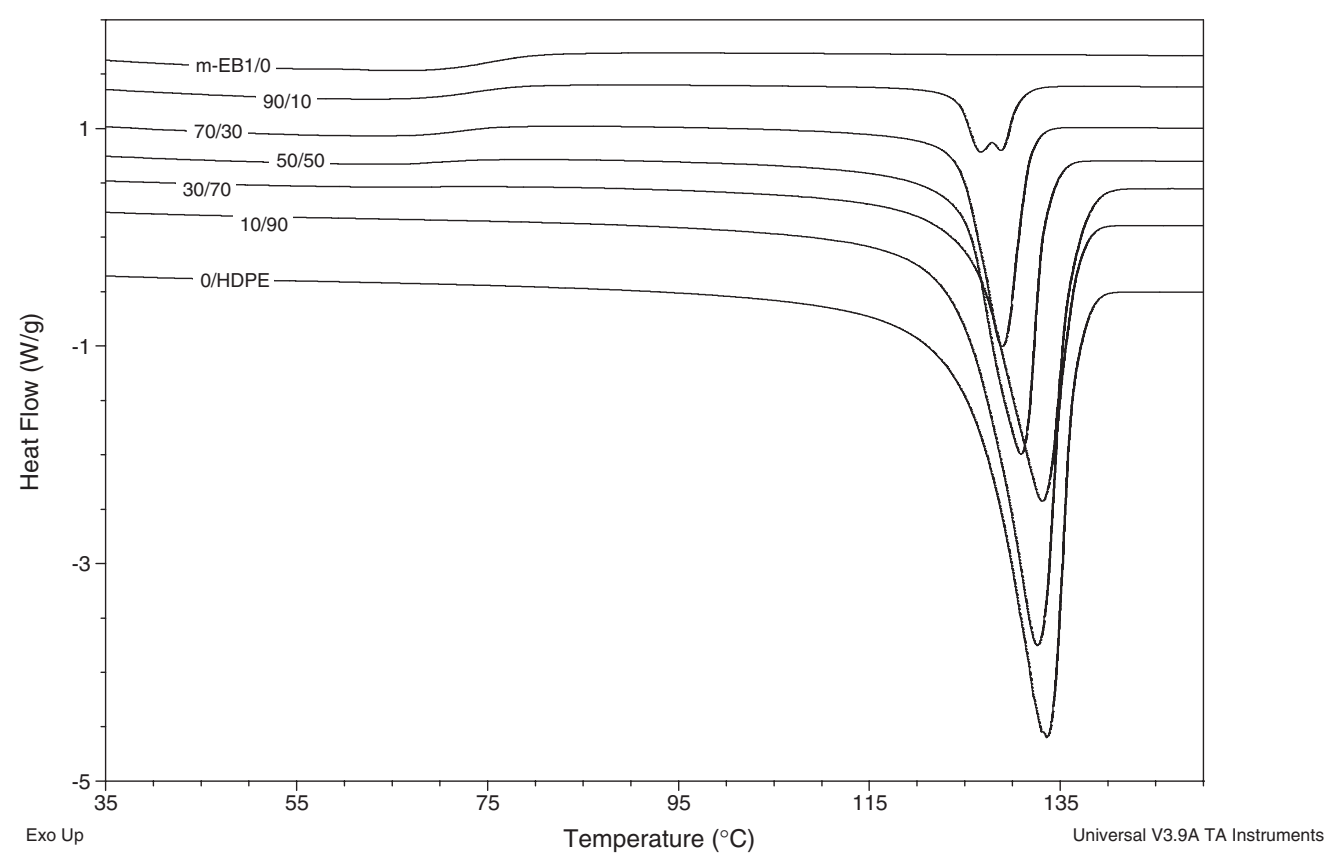

(a)

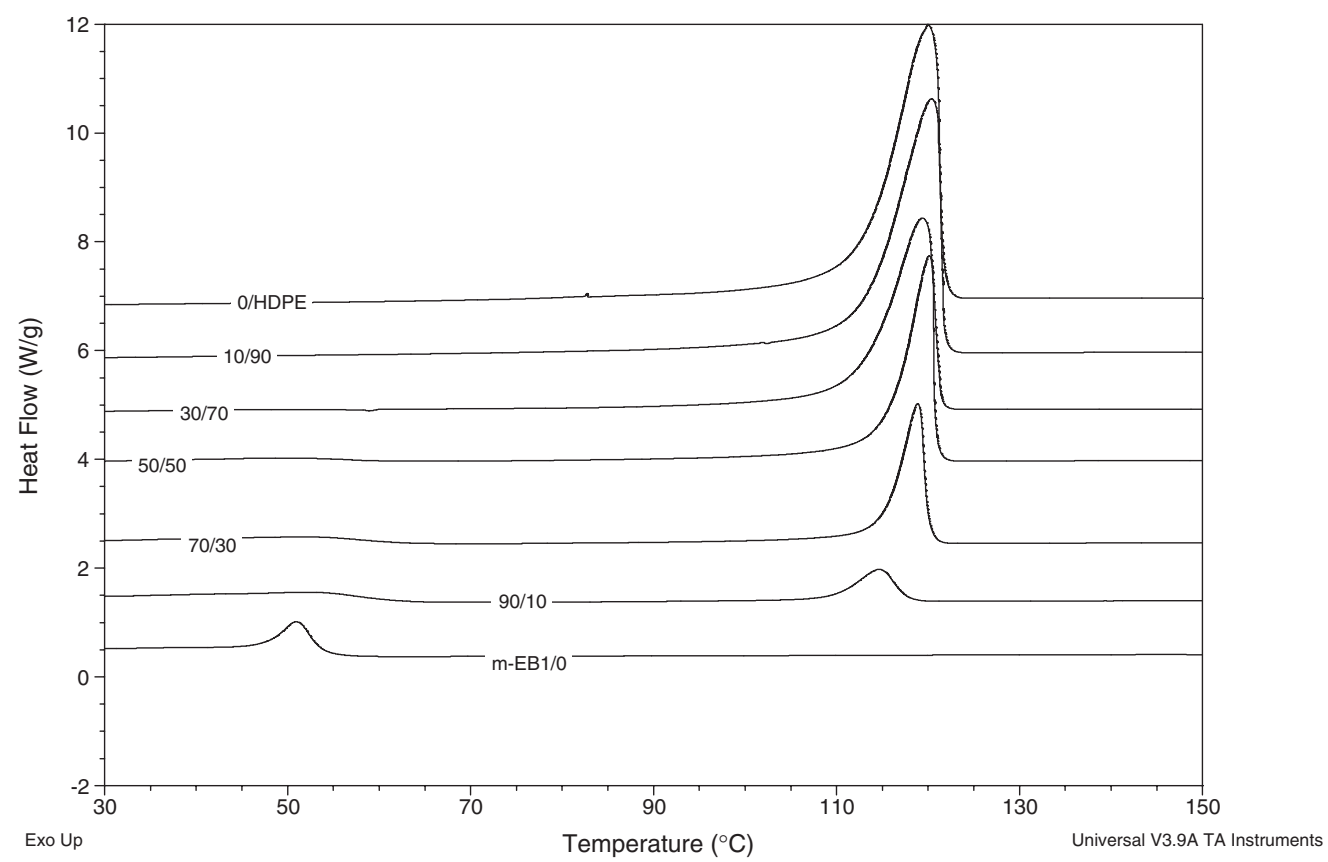

(b)

Figure 7. (a) DSC heating scans for m-EB1/HDPE blends. (b) DSC cooling scans for m-EB1/HDPE blends.

and crystallinity versus composition data (results not shown) for these blends. Once again, heating and cooling thermograms for m-EB2/HDPE blends are very similar to those of $\mathrm{m}$-EB1/HDPE blends, hence not shown. The thermal properties are presented in Table II. The properties are very similar to those observed in the low- $M_{\mathrm{w}} \mathrm{m}-\mathrm{EB} 2 / \mathrm{HDPE}$ blends. Hence, no influence of $M_{\mathrm{w}}$ is observed on the solid state compatibility even with high branch content LLDPEs.

Although the $M_{\mathrm{w}}$ of LLDPE did influence its melt miscibility with HDPE its effect on solid state com- patibility was negligible. Fredrickson and Bates ${ }^{42}$ suggested that melt immiscibility is the result of conformational mismatch between the polyolefin blend components. Further evidence of molecular order in melts of linear polyethylene ${ }^{43}$ also suggests different conformations for different types of PEs depending on the type, content and distribution of branching as supported by molecular dynamics simulations. ${ }^{44}$ Hence, it could be concluded that different factors control the melt miscibility and the crystallization of m-LLDPE blends with HDPE. 

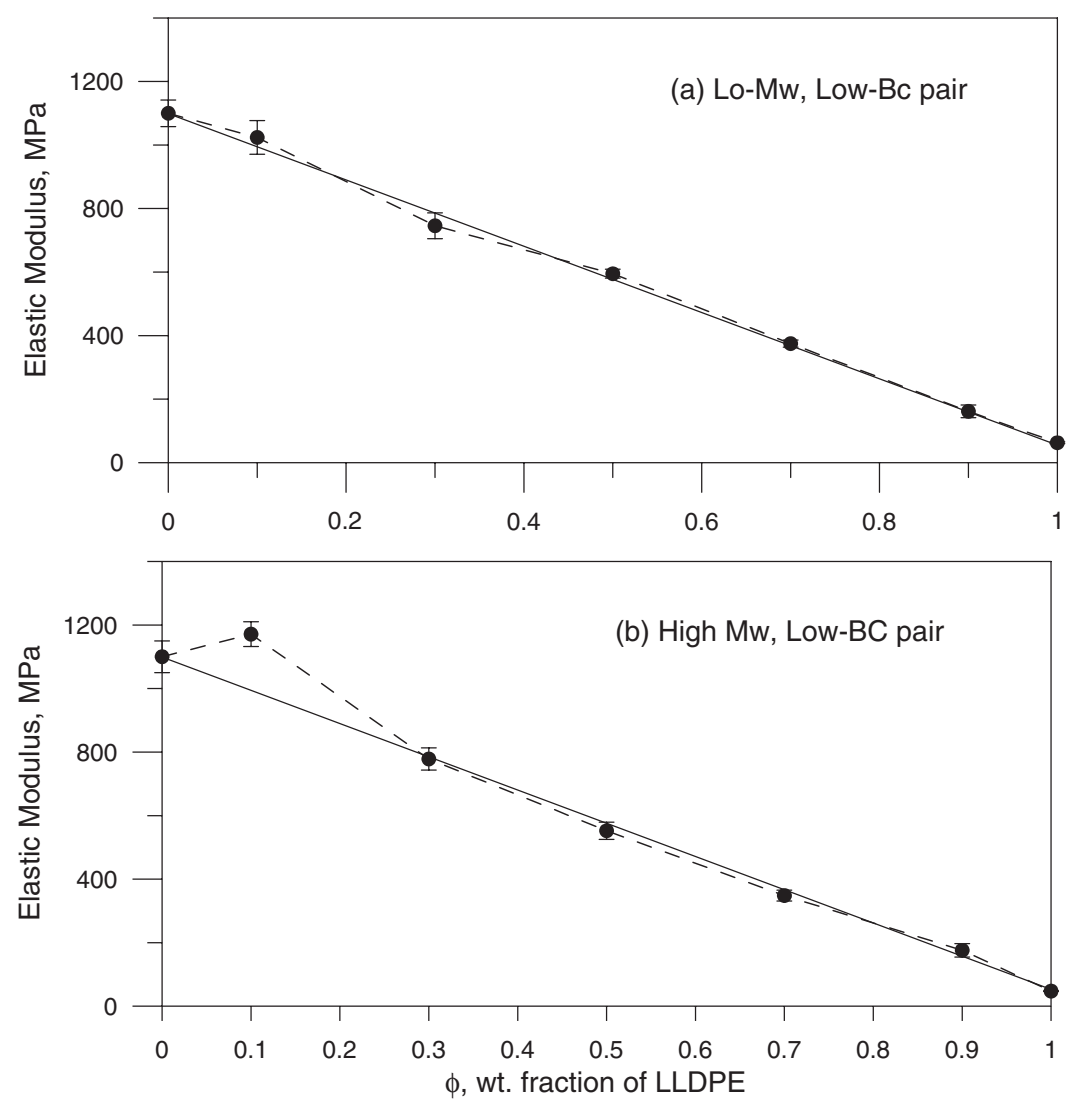

Figure 8. Tensile modulus as a function of composition; (a) m-EH1/HDPE; (b) m-EH2/HDPE blends.

\section{Mechanical Properties}

Figures $8 \mathrm{a}$ and $8 \mathrm{~b}$ show the tensile modulus versus LLDPE composition in low $M_{\mathrm{w}}, \mathrm{m}-\mathrm{EH} 1 / \mathrm{HDPE}$ and high $M_{\mathrm{w}}, \mathrm{m}-\mathrm{EH} 2 / \mathrm{HDPE}$ blends, respectively. HDPE with high $M_{\mathrm{w}}$ and high crystallinity resulting from its linear structure shows the highest modulus. The low $M_{\mathrm{w}} \mathrm{m}-\mathrm{EH} 1 / \mathrm{HDPE}$ blend moduli are found to follow linear additivity rule. This is very much in conformity with our findings of miscibility of these blends in the melt and solid state in the previous sections. Since the two resins are miscible additions of low $M_{\mathrm{w}}$ m-EH1 steadily decreases the modulus of HDPE. Elastic moduli for high $M_{\mathrm{w}} \mathrm{m}-\mathrm{EH} 2$ blends with HDPE also followed the linear additivity rule for all blends except the $10 \% \mathrm{~m}-\mathrm{EH} 2$, which shows positive deviation from linear additivity.

The moduli for high-BC m-EB1 and m-EB2 blends with HDPE are plotted against LLDPE composition in Figures $9 \mathrm{a}$ and $9 \mathrm{~b}$, respectively. In both cases, the moduli decrease with the increase in LLDPE component irrespective of their $M_{\mathrm{w}}$. Large negative deviation from linear additivity suggest incompatibility of these blends resulting from high-BC of the LLDPE component. It is established that branching is the key factor controlling the solid state morphology of these blends. ${ }^{14,15,19}$ Similar trends were reported for $\mathrm{m}$-LLDPE/HDPE blends in the literature. ${ }^{21,31,32}$

\section{CONCLUSIONS}

Rheological, thermal and mechanical characteristics of two sets of m-LLDPE/HDPE blends at low and high-BC levels were studied. The rheology of these blends suggest a strong influence of $M_{\mathrm{w}}$ on melt miscibility of m-LLDPE/HDPE blends. Low $M_{\mathrm{w}} \mathrm{m}-$ LLDPE is miscible with HDPE at all compositions, whereas, high $M_{\mathrm{w}}$ m-LLDPE/HDPE blends showed negative deviation behavior from log additivity suggesting layered morphology. These results are in agreement with earlier DSC, SANS and rheology reports that immiscibility increases with increase in $M_{\mathrm{w}}$ and $\mathrm{BC}$ of the branched component. ${ }^{10,12,14,24}$

For all blends studied, DSC results exhibited that compatibility in the solid phase is independent of $M_{\mathrm{w}}$ and branch content. For all blends studied, HDPE-rich blends were found to contain a single crystal population suggesting high degree of cocrystallization and compatibility, whereas, m-LLDPE rich phase showed separate crystallization and multiple melting peaks. The results suggest that different factors control morphology in the melt and the solid state. It was reported that melt immiscibility is a consequence of conformational and architectural mismatch of blend components; ${ }^{42}$ this study reveals that solid state crystalliza- 

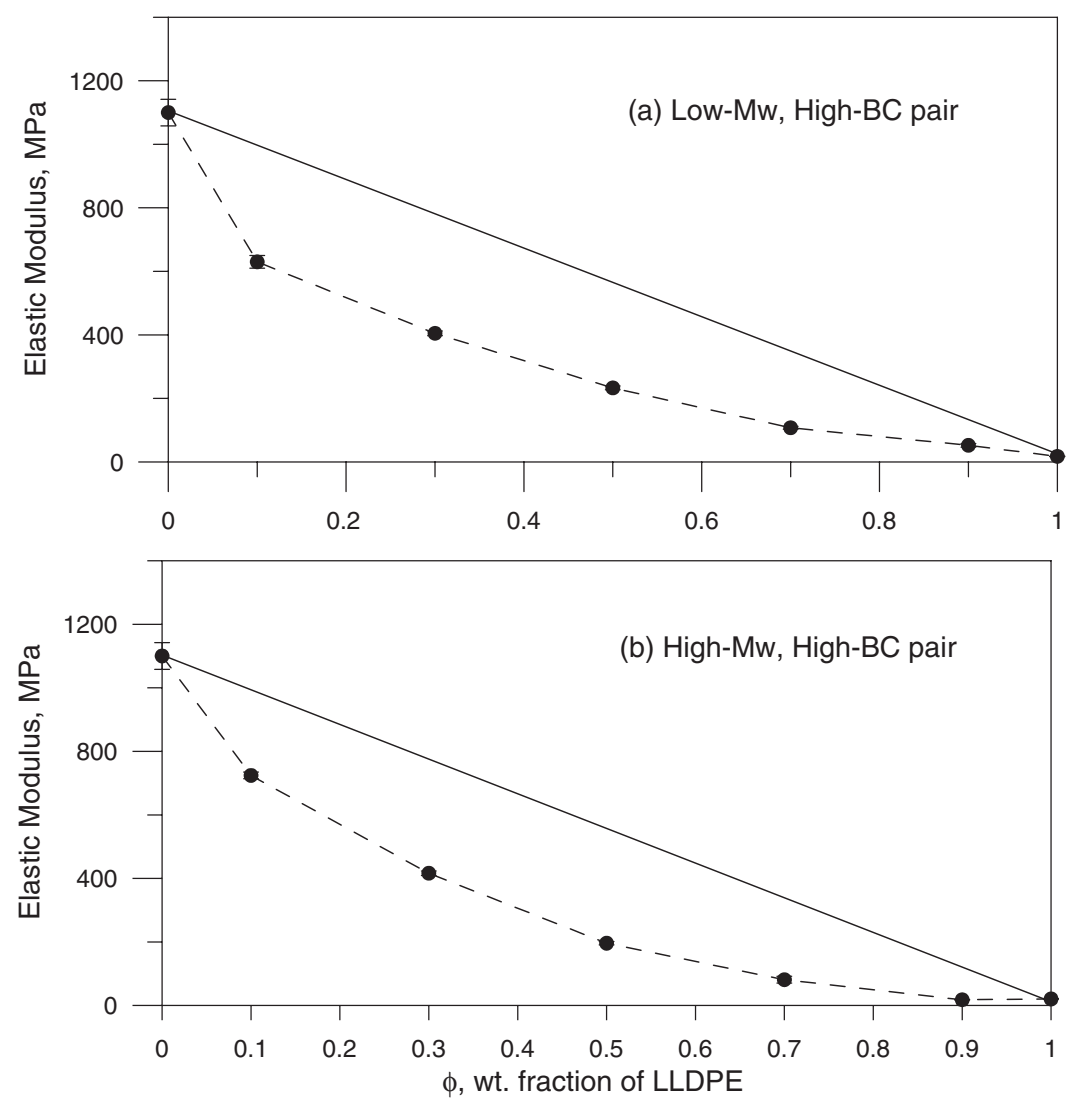

Figure 9. Tensile modulus as a function of composition; (a) m-EB1/HDPE; (b) m-EB2/HDPE blends.

tion is not controlled by similar factors. For the low BC pair, at low and high $M_{\mathrm{w}}$, the modulus generally followed linear additivity. However, for high BC mLLDPE blends with HDPE the modulus was always lower than that predicted by linear additivity.

Acknowledgment. The authors wish to acknowledge KFUPM for the financial support of this work through project \# CHE/Rheology/223. Also, Mr. M. Arab of the Chemistry Department, KFUPM, is acknowledged for his help with the NMR analysis. Also, TH would like to thank Research Institute, KFUPM for its support.

\section{REFERENCES}

1. L. A. Utracki, "Polymer Alloys and Blends; Thermodynamics and Rheology," Hanser, New York, 1989.

2. Y. Fang, P. J. Carreau, and P. G. Lafleur, Polym. Eng. Sci., 45, 1254 (2005).

3. P. Micic, S. N. Bhattacharya, and G. Field, Int. Polym. Proc., 11, 14 (1996).

4. I. A. Husssein and M. C. Williams, Polym. Eng. Sci., 41, 696 (2001).

5. D. Rana, C. H. Lee, K. Cho, B. H. Lee, and S. Choe, J. Appl. Polym. Sci., 69, 2441 (1998).

6. F. P. La Mantia, A. Valenza, and D. Acierno, Eur. Polym. J., 22, 647 (1986).

7. K. Cho, B. H. Lee, K. M. Hwang, H. Lee, and S. Choe,
Polym. Eng. Sci., 38, 1969 (1998).

8. M. J. Hill, R. L. Morgan, and P. J. Barham, Polymer, 38, 3003 (1997).

9. M. J. Hill, Polymer, 35, 1991 (1994).

10. B. S. Tanem and A. Stori, Polymer, 42, 1309 (2001).

11. G. D. Wignall, R. G. Alamo, J. D. Londono, L. Mandelkern, M. H. Kim, J. S. Lin, and G. M. Brown, Macromolecules, 33, 551 (2000).

12. R. G. Alamo, W. W. Graessley, R. Krishnamoorti, D. J. Lohse, J. D. Londono, L. Mandelkern, F. C. Stehling, and G. D. Wignall, Macromolecules, 30, 561 (1997).

13. C. Schipp, M. J. Hill, P. J. Barham, V. M. Cloke, J. S. Higgins, and L. Oiarzabal, Polymer, 37, 2291 (1996).

14. Y. Zhao, S. Liu, and D. Yang, Macromol. Chem. Phys., 198, 1427 (1997).

15. B. S. Tanem and A. Stori, Polymer, 42, 5389 (2001).

16. J. Xu, X. Xu, L. Chen, L. Feng, and W. Chen, Polymer, 42, 3867 (2001).

17. C. Liu, J. Wang, and J. He, Polymer, 43, 3811 (2002).

18. H. S. Lee and M. M. Denn, Polym. Eng. Sci., 40, 1132 (2000).

19. S. Y. Lee, J. Y. Tho, and Y. C. Lee, Polym. Mater. Sci. Eng., 76, 325 (1997).

20. S. Bensason, S. Nazarenko, S. Chum, A. Hiltner, and E. Baer, Polymer, 38, 3513 (1997).

21. I. A. Hussein, Polym. Int., 53, 1327 (2004).

22. I. A. Hussein, Polym. Int., 54, 1330 (2005).

23. I. A. Hussein and T. Hameed, J. Appl. Polym. Sci., 97, 2488 (2005).

24. I. A. Hussein, Macromolecules, 36, 2024 (2003). 
25. T. Hameed and I. A. Hussein, Polymer, 43, 6911 (2002).

26. I. A. Hussein, T. Hameed, B. F. Abu-Sharkh, and K. Mezghani, Polymer, 44, 4665 (2003).

27. T. Hameed and I. A. Hussein, Macromol. Mater. Eng., 289, 198 (2004).

28. I. A. Hussein and M. C. Williams, Rheol. Acta, 43, 602 (2004).

29. I. A. Hussein and M. C. Williams, Polym. Eng. Sci., 44, 660 (2004).

30. A. Garcia-Rejon, Polym. Eng. Sci., 27, 640 (1987).

31. A. K. Gupta, S. K. Rana, and B. L. Deopura, J. Appl. Polym. Sci., 46, 99 (1992).

32. C. L. Shan, J. B. P. Soares, and A. Penlidis, Polymer, 43, 7345 (2002).

33. F. Chen, R. Shanks, and G. Amarasinghe, Polymer, 42, 4579 (2001).

34. M. L. Arnal, J. J. Sanchez, and A. J. Muller, Polymer, 42, 6877 (2001).
35. B. F. Abu Sharkh, A. M. Giri, and I. A. Hussein, Eur. Polym. J., 40, 1177 (2004).

36. M. Ashraful Islam and I. A. Hussein, J. Appl. Polym. Sci., 100, 5019 (2006).

37. M. Zhang, D. T. Lynch, and S. E. Wanke, Polymer, 42, 3067 (2001).

38. L. A. Uracki, Polym. Eng. Sci., 35, 1615 (1991).

39. C. C. Lin, Polym. J., 11, 185 (1979).

40. E. C. Bingham, "Fluidity and Elasticity," McGraw-Hill, New York, 1922, p 86.

41. P. Choi, Polymer, 41, 8741 (2000).

42. G. H. Fredrickson, A. J. Liu, and F. S. Bates, Macromolecules, 27, 2503 (1994).

43. I. A. Hussein and M. J. Williams, J. Non-Newtonian Fluid Mech., 86, 105 (1999).

44. B. F. Abu-Sharkh and I. A. Hussein, Polymer, 43, 6333 (2002). 